\title{
Stenting versus aggressive medical therapy for intracranial arterial stenosis: more harm than good
}

\author{
Muthanna Al Hasan, ${ }^{1,2}$ and Raghavan Murugan*1,2 \\ University of Pittsburgh Department of Critical Care Medicine: Evidence-Based Medicine Journal Club, edited by Sachin Yende
}

\section{Expanded abstract Citation \\ Chimowitz MI, Lynn MJ, Derdeyn CP, Turan TN, Fiorella D, Lane BF, Janis LS, Lutsep HL, Barnwell SL, Waters MF, Hoh BL, Hourihane JM, Levy EI, Alexandrov AV, Harrigan MR, Chiu D, Klucznik RP, Clark JM, McDougall CG, Johnson MD, Pride GL Jr, Torbey MT, Zaidat OO, Rumboldt Z, Cloft HJ, for the SAMMPRIS Trial Investi- gators. N Engl J Med 2011, 365:993-1003. PubMed PMID: 21899409. This is available on www.pubmed.gov.}

\section{Background}

Atherosclerotic intracranial arterial stenosis is an important cause of stroke that is increasingly being treated with percutaneous transluminal angioplasty and stenting (PTAS) to prevent recurrent stroke. However, PTAS has not been compared with medical management in a randomized trial.

\section{Methods}

Objective: To determine whether intracranial stenting (using the Wingspan self-expanding nitinol stent, Boston Scientific) and intensive medical therapy is superior to intensive medical therapy alone for preventing stroke in recently symptomatic patients with severe intracranial atherosclerotic stenosis.

Design: Phase III, multi-center, randomized, open label, clinical trial.

Setting: 50 sites in the US

Subjects: Patients who had a recent transient ischemic attack or stroke attributed to stenosis of 70 to $99 \%$ of the diameter of a major intracranial artery.

Intervention: Eligible patients were randomized to receive either aggressive medical medical management alone or aggressive medical management plus PTAS with the use of the Wingspan stent system.

*Correspondence: muruganr@upmc.edu

642A Scaife Hall, 3550 Terrace Street, University of Pittsburgh, Pittsburgh, PA 15261, USA

Full list of author information is available at the end of the article
Outcomes: The primary end point was stroke or death within 30 days after enrollment or after a revascularization procedure for the qualifying lesion during the follow-up period or stroke in the territory of the qualifying artery beyond 30 days. Patients in the medical arm who undergo angioplasty for recurrent TIAs (i.e. crossovers) and who have a stroke or death within 30 days will also meet this endpoint.

\section{Results}

Of the 451 patients who underwent randomization, 227 were assigned to the medical management group and 224 to the PTAS group. The 30-day rate of stroke or death was $14.7 \%$ in the PTAS group (nonfatal stroke, 12.5\%; fatal stroke, $2.2 \%$ ) and $5.8 \%$ in the medical-management group (nonfatal stroke, 5.3\%; non-stroke-related death, $0.4 \%)(P=0.002)$. Beyond 30 days, stroke in the same territory occurred in 13 patients in each group. The probability of the occurrence of a primary end-point event over time differed significantly between the two treatment groups $(P=0.009)$, with 1 -year rates of the primary end point of $20.0 \%$ in the PTAS group and $12.2 \%$ in the medical-management group.

\section{Conclusions}

In patients with intracranial arterial stenosis, aggressive medical management was superior to PTAS with the use of the Wingspan stent system, both because the risk of early stroke after PTAS was high and because the risk of stroke with aggressive medical therapy alone was lower than expected.

\section{Commentary}

Stroke is a major public health problem as it is a leading cause of death and long-term disability in the United States. There are approximately 795,000 incident strokes each year, resulting in more than 140,000 deaths annually [1]. In 2010, the cost of stroke care was estimated at $\$ 74$ billion, with a mean lifetime cost of $\$ 140,000$ per patient [2]. Atherosclerotic disease of the major intracranial arteries is a frequent cause of ischemic stroke with annual risk as high as $24 \%$ [3]. Patients with severe intracranial 
arterial stenosis (70\% to $99 \%$ ) are at high risk of stroke in the territory of the stenotic artery [4], which is potentially amenable to intracranial angioplasty or stenting.

Current primary prevention strategies include a combination of life style modification (smoking cessation, dietary intervention, weight loss, and exercise), antihypertensive medications, antithrombotic therapy, and statins [5]. Recommended secondary prevention includes a combination of medical therapy and revascularization [6]. Tremendous advances have been made in cerebral revascularization techniques in recent years, which include percutaneous transluminal angioplasty (PTA) alone, PTA with stenting (PTAS) using balloon-mounted coronary stents, and extracranial-intracranial surgical bypass. However, unlike extracranial carotid disease, the long term efficacy and safety of revascularization strategies of intracranial atherosclerotic disease have not been well established.

Several retrospective case series suggest that PTA alone is a safe and effective treatment strategy for intracranial atherosclerotic disease [7]. However, PTA has several technical drawbacks including immediate elastic recoil of the artery and high restenosis rates [8]. Surgical bypass was shown to be inferior to medical therapy for middle cerebral artery stenosis [9]. While some studies reported that PTAS with balloon-mounted coronary stents was safe and effective [10], others showed high rates of periprocedural morbidity (23\%) and mortality (5\%) [11].

The Wingspan, a flexible, self-expanding, is the first stent designed specifically for the treatment of symptomatic intracranial atherosclerotic disease. The high flexibility of these stents makes them suitable for treatment of lesions of the distal internal carotid artery and middle cerebral artery that are either inaccessible or difficult to reach with a balloon-mounted coronary stent.

The Stenting and Aggressive Medical Management for Preventing Recurrent stroke in Intracranial Stenosis (SAMMPRIS) trial is the first prospective randomized trial in patients' with symptomatic intracranial atherosclerotic disease to compare the Wingspan stent and aggressive medical therapy with aggressive medical therapy alone. Aggressive medical therapy included aspirin $325 \mathrm{mg}$ per day for entire follow-up, clopidogrel $75 \mathrm{mg}$ per day for 90 days after enrollment, and aggressive risk factor management primarily targeting blood pressure $<140 / 90 \mathrm{mmHg}(<130 / 80$ if diabetic) and LDL $<70 \mathrm{mg} / \mathrm{dl}$. However, the Data Safety Monitoring Board halted the trial after enrollment of 451 (59\%) of the planned 764 participants because of the significant stroke and mortality rates observed in the stent arm.

The SAMMPRIS is a well-conducted, multicenter, controlled trial that has provided strong scientific evidence of the superiority of medical therapy to PTAS. The twofold increased risk of stroke with stent clearly indicates that stenting should not be used for stroke prevention in high-risk individuals. Of particular concern is the significant number of periprocedural intracranial hemorrhages. Unlike coronary vasculature, intracranial vessels are more challenging to stent because they are difficult to navigate due to their very tortuous course and sharp angles, and those vessels are delicate and more susceptible to injury due to lack of supporting connective tissue.

Based on the current study, the authors recommend adding clopidogrel to aspirin for the first 90 days following stroke in patients with high grade intracranial stenosis. However, it has to be pointed out that the control arm does not represent the current standard of care for stroke prevention as addition of clopidogrel to aspirin has been shown to increase the risk of hemorrhage [12]. The main reason for adding clopidogrel to aspirin in the control arm of SAMMPRIS trial was to balance the antithrombotic regimen in order to establish the superiority of the stent. The study did not include an aspirin monotherapy arm to compare the result of aspirin monotherapy with dual antiplatelet (aspirin and clopidogrel) therapy. Therefore it is unclear whether a combination of aspirin and clopidogrel is superior to aspirin monotherapy, combination of aspirin and extendedrelease dipyridamole, and clopidogrel monotherapy, all of which are acceptable options for secondary prevention after ischemic stroke or TIA [6].

Two ongoing trials, Vitesse Intracranial Stent Study for Ischemic Therapy (VISSIT), which is comparing the use of the balloon-mounted stents to aspirin and clopidogrel, and Interventional Management of Stroke III (IMS III) trial, which is evaluating different revascularization strategies including clot retrieval devices, should hopefully provide more insight towards optimal strategy for stroke prevention.

\section{Recommendation}

Treatment with the Wingspan stent system for patients with intracranial stenosis carries substantial risk of death and stroke and should be abandoned.

\section{Competing interests}

The authors declare that they have no competing interests.

\section{Author details}

'The Clinical Research, Investigation, and Systems Modeling of Acute IIIness (CRISMA) Center, University of Pittsburgh, Pittsburgh, PA, USA. ²Department of Critical Care Medicine, University of Pittsburgh, Pittsburgh, PA, USA.

\section{Published: 9 May 2012}

\section{References}

1. National Vital Statistics Reports: vol 59 no 10. Hyattsville, MD: National Center for Health Statistics; 2011

2. Lloyd-Jones D, Adams RJ, Brown TM, Carnethon M, Dai S, De SG, Ferguson TB, Ford E, Furie K, Gillespie C, Go A, Greenlund K, Haase N, Hailpern S, Ho PM, Howard V, Kissela B, Kittner S, Lackland D, Lisabeth L, Marelli A, McDermott MM, Meigs J, Mozaffarian D, Mussolino M, Nichol G, Roger VL, Rosamond W, Sacco R, Sorlie P, Roger VL, Thom T, Wasserthiel-Smoller S, Wong ND, 
Wylie-Rosett J: Heart disease and stroke statistics--2010 update: a report from the American Heart Association. Circulation 2010, 121:e46-e215.

3. Thijs VN, Albers GW. Symptomatic intracranial atherosclerosis: outcome of patients who fail antithrombotic therapy. Neurology 2000, 55:490-497.

4. The Warfarin-aspirin Symptomatic Intracranial Disease (WASID) Study Group. Prognosis of patients with symptomatic vertebral or basilar artery stenosis. Stroke 1998, 29:1389-1392.

5. Goldstein LB, Bushnell CD, Adams RJ, Appel LJ, Braun LT, Chaturvedi S, Creager MA, Culebras A, Eckel RH, Hart RG, Hinchey JA, Howard VJ, Jauch EC, Levine SR, Meschia JF, Moore WS, Nixon JV, Pearson TA: Guidelines for the primary prevention of stroke: a quideline for healthcare professionals from the American Heart Association/American Stroke Association. Stroke 2011, 42:517-584

6. Furie KL, Kasner SE, Adams RJ, Albers GW, Bush RL, Fagan SC, Halperin JL, Johnston SC, Katzan I, Kernan WN, Mitchell PH, Ovbiagele B, Palesch YY, Sacco RL, Schwamm LH, Wassertheil-Smoller S, Turan TN, Wentworth D: Guidelines for the prevention of stroke in patients with stroke or transient ischemic attack: a guideline for healthcare professionals from the American Heart Association/American Stroke Association. Stroke 2011, 42:227-276.

7. Marks MP, Marcellus ML, Do HM, Schraedley-Desmond PK, Steinberg GK Tong DC, Albers GW: Intracranial angioplasty without stenting for symptomatic atherosclerotic stenosis: long-term follow-up. AJNRAm 」 Neuroradiol 2005, 26:525-530

8. Marks MP, Wojak JC, Al-Ali F, Jayaraman M, Marcellus ML, Connors JJ, Do HM. Angioplasty for symptomatic intracranial stenosis: Clinical outcome. Stroke 2006, 37:1016-1020
9. Failure of extracranial-intracranial arterial bypass to reduce the risk of ischemic stroke. Results of an international randomized trial. The $\mathrm{EC} / \mathrm{IC}$ Bypass Study Group. N Engl J Med 1985, 313:1191-1200.

10. SSYLVIA Study Investigators. Stenting of Symptomatic Atherosclerotic Lesions in the Vertebral or Intracranial Arteries (SSYLVIA): study results. Stroke 2004, 35:1388-1392.

11. Chow MM, Masaryk TJ, Woo HH, Mayberg MR, Rasmussen PA: Stent-assisted angioplasty of intracranial vertebrobasilar atherosclerosis: midterm analysis of clinical and radiologic predictors of neurological morbidity and mortality. AJNR Am J Neuroradiol 2005, 26:869-874.

12. Bhatt DL, Fox KA, Hacke W, Berger PB, Black HR, Boden WE, Cacoub P, Cohen EA, Creager MA, Easton JD, Flather MD, Haffner SM, Hamm CW, Hankey GJ, Johnston SC, Mak KH, Mas JL, Montalescot G, Pearson TA, Steg PG, Steinhubl SR, Weber MA, Brennan DM, Fabry-Ribaudo L, Booth J, Topol EJ: Clopidogrel and aspirin versus aspirin alone for the prevention of atherothrombotic events. N Engl J Med 2006, 354:1706-1717.

doi:10.1186/cc11326

Cite this article as: Al Hasan M, Murugan R: Stenting versus aggressive medical therapy for intracranial arterial stenosis: more harm than good. Critical Care 2012, 16:310 